\title{
Heterotopic Ossification of the Triceps Muscle after Internal Fixation of Proximal Ulna Fracture: A Case Report
}

\author{
Chang-Song Mun*, Tae-Song So and Chol-Ho Jang \\ Department of Trauma and Orthopaedic Surgery, Pyongyang Medical College Hospital, Kim II Sung \\ University, Pyongyang, Democratic People's Republic of Korea
}

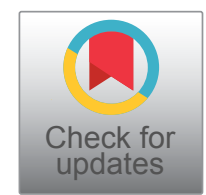

*Corresponding author: Chang-Song Mun, Department of Trauma and Orthopaedic Surgery, Pyongyang Medical College Hospital, Kim II Sung University, Pyongyang, Democratic People's Republic of Korea

\section{Keywords}

Heterotopic ossification, Ectopic calcification, Elbow stiffness, Proximal ulna, Internal fixation, Locking plate, Olecranon fracture

\section{Introduction}

Olecranon fractures comprise approximately $10 \%$ of all fractures around the elbow [1].

They vary in their complexity from relatively straightforward transverse fractures to comminuted and unstable configurations.

As in other articular fractures, the aims of treatment, as defined by $\mathrm{AO}$ group, are to restore the articular surface, achieve absolute stability of the fracture, and commence early active motion, and, finally, the restoration of function without pain [2-4].

This is only possible with ORIF (open reduction and internal fixation) such as TBW (tension $b$ and wiring), plate and intramedullary fixation techniques as well as fragment excision with triceps advancement [4-8].

The TBW described by Weber and Vasey [4] has been widely used in the ORIF of olecranon, however, plate fixation has been used principally for the management of comminuted olecranon fractures in which TBW is not appropriate $[5,9]$.

Plates are generally applied to the dorsal surface of the ulna because this is the tension side of the olecranon which makes the construct most biomechanically sound, and because screws can be passed into the coronoid $[10,11]$.

Anatomically contoured locking plates are one of the newest developments in olecranon plate technology and are being marketed as offering superior fixation as a result of the fixed angle construct [5].

Whilst good results have been shown with the use of these plates, there is currently insufficient evidence to suggest they are superior to other forms of plate fixation [5].

This report describes heterotopic ossification ( $\mathrm{HO})$ as a complication related to the internal fixation of a proximal ulna comminuted fracture.

\section{Case Report}

A 35-year-old, right-hand-dominant woman fell from a height sustaining an intra-articular, comminuted, fracture of the left proximal ulna (Figure 1).

As shown in Figure 1, direct forces generated comminution of the central portion of the proximal part of ulna including olecranon articular surface and, also avulsions of the coronoid process including the extension of the ulna shaft. The triceps brachii inserted into the posterior third of the olecranon and the proximal ulna separated the olecranon, the brachialis inserted into the coronoid process of the ulna produced tensile forces across the elbow joint during contraction, so as to separate the coronoid, thus resulting in complex fracture of proximal ulna. According to the AO principle of articular fracture management, ORIF using

Citation: Mun CS, So TS, Jang CH (2021) Heterotopic Ossification of the Triceps Muscle after Internal Fixation of Proximal Ulna Fracture: A Case Report. Trauma Cases Rev 7:092. doi.org/10.23937/24695777/1510092

Accepted: September 02, 2021: Published: September 04, 2021

Copyright: (c) 2021 Mun CS, et al. This is an open-access article distributed under the terms of the Creative Commons Attribution License, which permits unrestricted use, distribution, and reproduction in any medium, provided the original author and source are credited. 


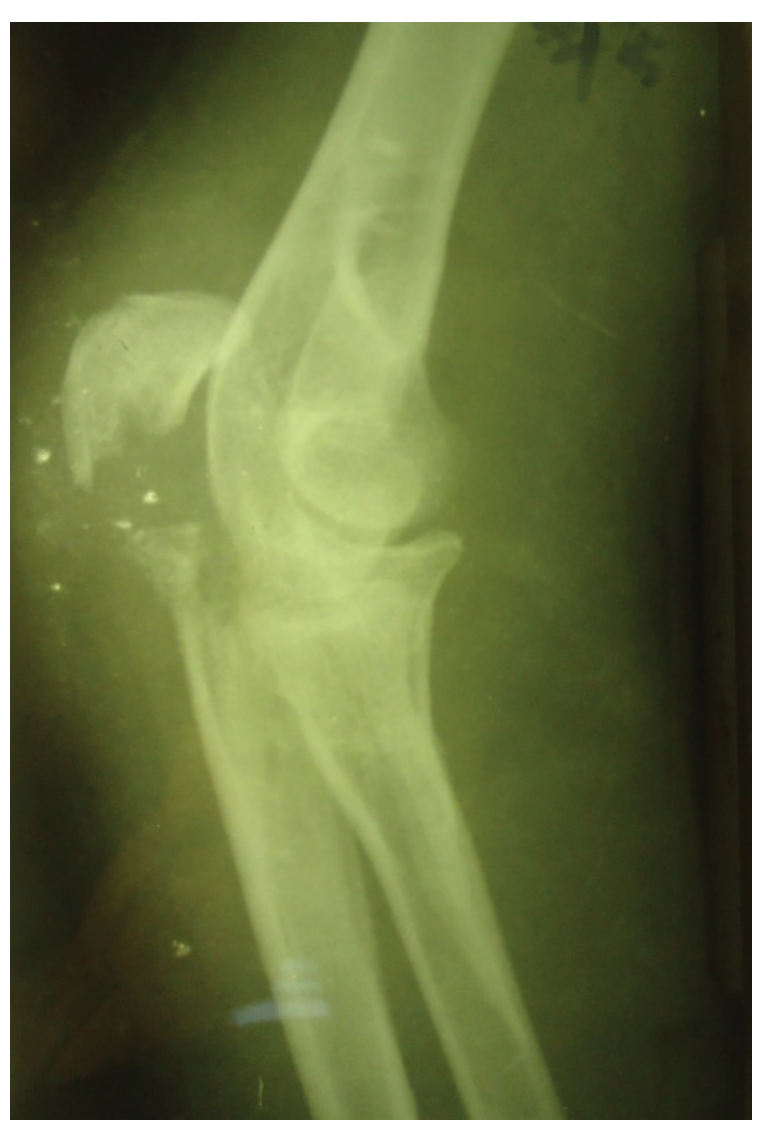

A

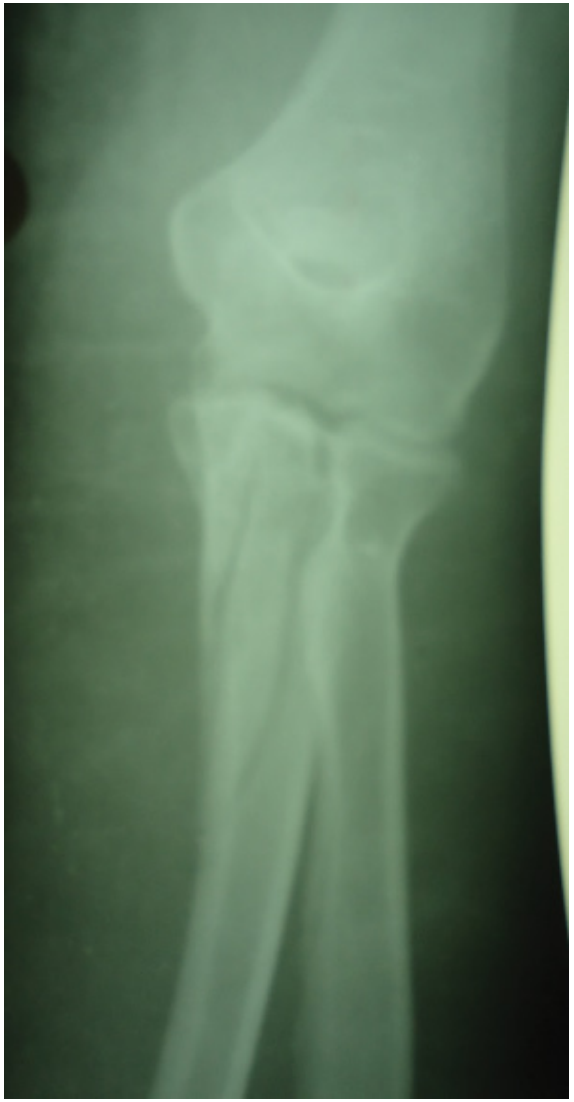

B

Figure 1: Preoperative X-ray view of the patient sustaining an intra-articular, comminuted, fracture of the left proximal ulna. Olecranon, coronoid process and the shaft of ulna are separated a) Lateral view; b) Anterioposterior view.

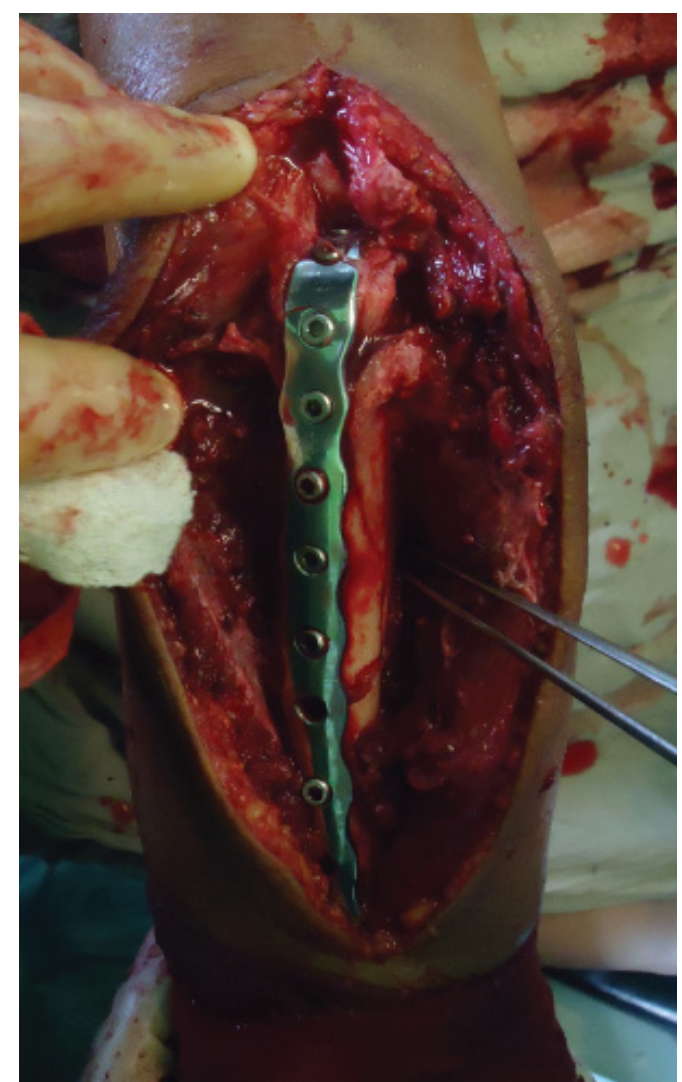

Figure 2: Intraoperative view (completion of internal fixation). anatomical locking plate was performed, one day after the injury, without any complication.

\section{Surgical technique}

A direct reduction was performed using hooks, pointed reduction forceps, and K-wires. With exposure of the major fragments under direct vision, reduction was achieved and maintained with temporary pin fixation. The fracture reduction was visualized on each of the sigmoid notch and dorsally. Visualization of the coronoid could be made through the fracture site of the separated olecranon fragments before reduction.

After reduction and temporary fixation, a posterior locking plate 3.5 which was contoured to the anatomical shape of proximal ulna was applied for these comminuted fractures.

Coronoid process was fixed with 3 screws and subsequent bicortical screws were placed in a locking plate (Figure 2).

\section{Postoperative management}

No external device like a dorsal splint was applied. The patient was started on an early rehabilitation program.

The patient was allowed to use her elbow as 
tolerated. Active assisted exercises are started the day after, including gravity assisted elbow flexion with the patient lying supine. At approximately 8 weeks the evidence of union was revealed on plain radiograph, but she didn't recover her functional range of elbow motion, although professional physical therapy was applied.

She subsequently developed progressive elbow stiffness that was resistant to formal therapy.

At 16 weeks after surgery, her elbow flexion arc was not returned to functional range yet. Physical examination showed a loss of about $45^{\circ}$ of extension compared with the uninjured side, so range of motion (ROM) was $45^{\circ}$ to $100^{\circ}$. Forearm rotation was maintained. Radiographs taken at 6 months showed a union of proximal ulna, and also profound heterotopic ossification posteriorly within the triceps muscle just over the olecranon and posterior to olecranon fossa within the triceps muscle (Figure 3).

\section{Revision surgery \& final results}

6 months after the initial procedure, we performed the second surgery, which included removal of plate and screws and excision of heterotopic ossification at the same time. Intraoperatively we could find the 1.5 $\mathrm{cm}$ long bony mass surrounding the first and second screw hole of plate on the olecranon.

After resection of $\mathrm{HO}$ tissue, intraoperatively, we confirmed a full passive range of movement under

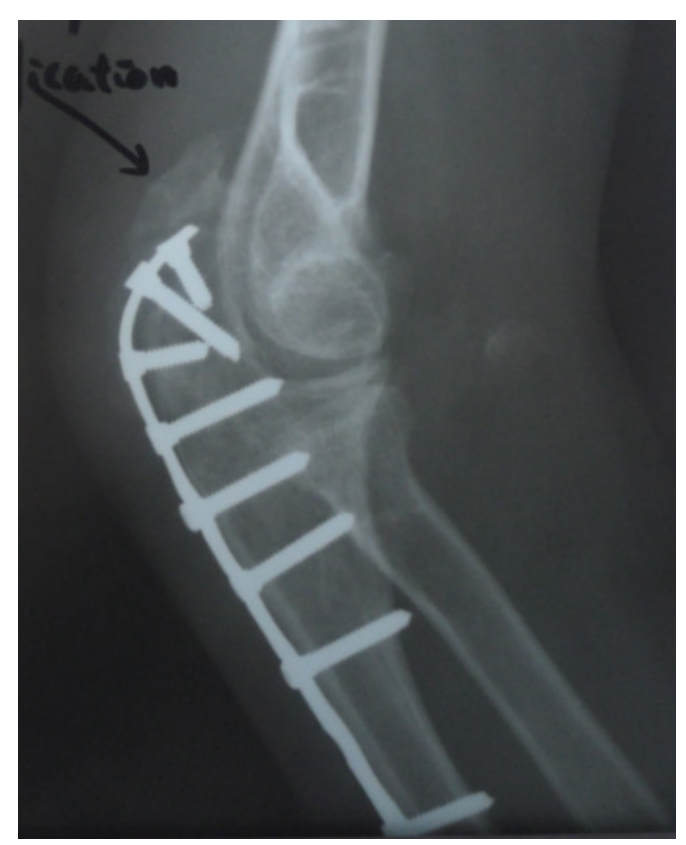

Figure 3: Occurence of heterotopic ossification in the triceps muscle.

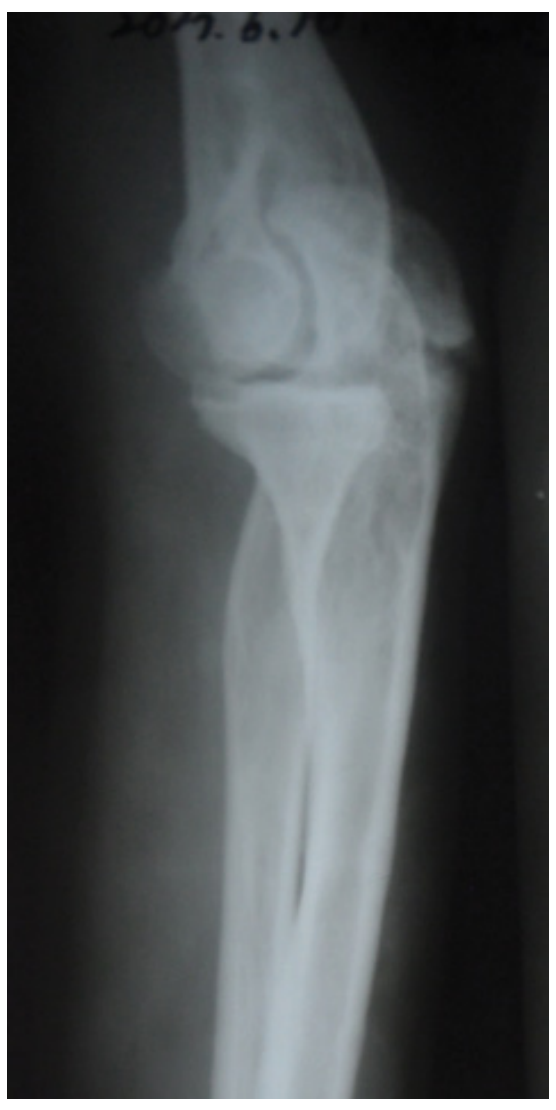

A

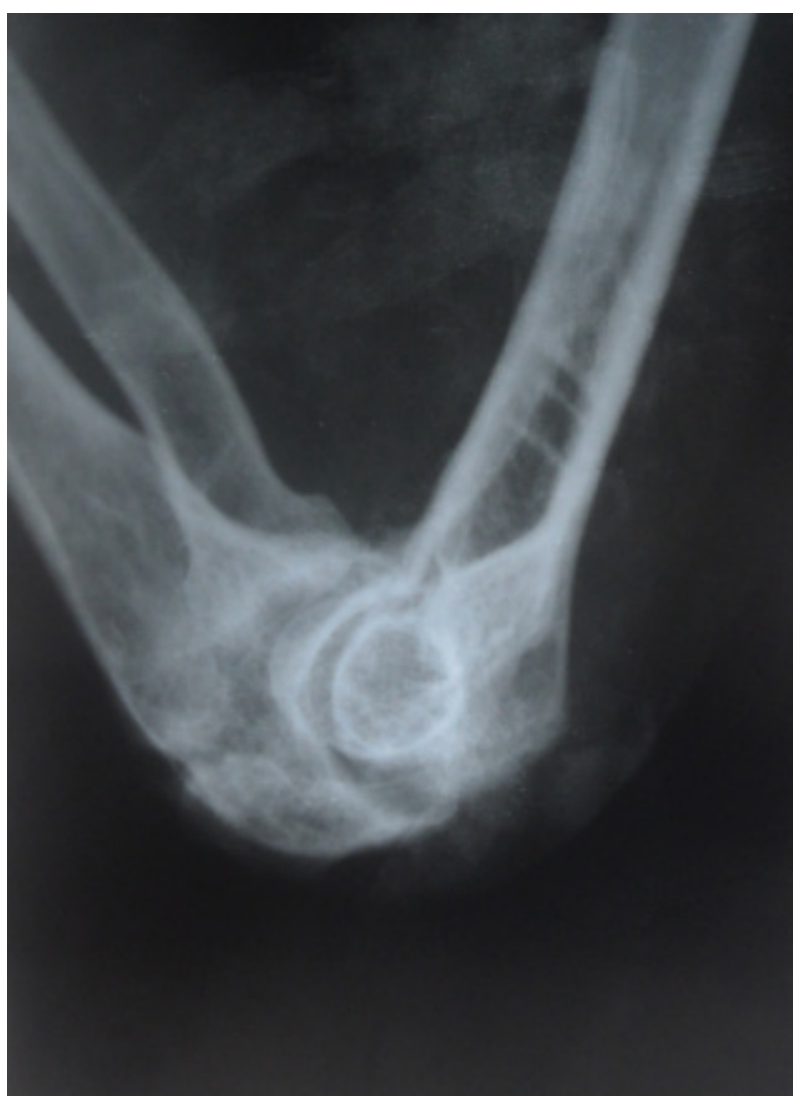

B

Figure 4: X-ray view of the elbow after removal of $\mathrm{HO}$ and implants (a) Lateral radiograph view of the extended elbow; (b) Lateral radiograph view of the flexed elbow. 
anaesthesia (Figure 4).

Postoperative radiographs confirmed that the entire mass has been excised.

$75 \mathrm{mg}$ indomethacin was prescribed daily for 6 weeks after surgery.

The patient started a regimen of active assisted elbow movements from the second postoperative day.

She was pain-free and obtained functional range of motion 3 weeks after the second procedure.

2 months after revision surgery, the patient was asymptomatic and has regained a range of elbow motion, from $20^{\circ}$ to $130^{\circ}$.

The functional assessment revealed possibilities for global nutrition (hand-mouth), hygiene (hand-face) and grooming (hand-neck).

On the basis of plain radiographic findings, we have not found any sign of recurrent ossification after an 18-month follow-up period.

The evaluation of 24-months follow-up period showed relief of pain and maintenance of functional range of motion (Figure 5).

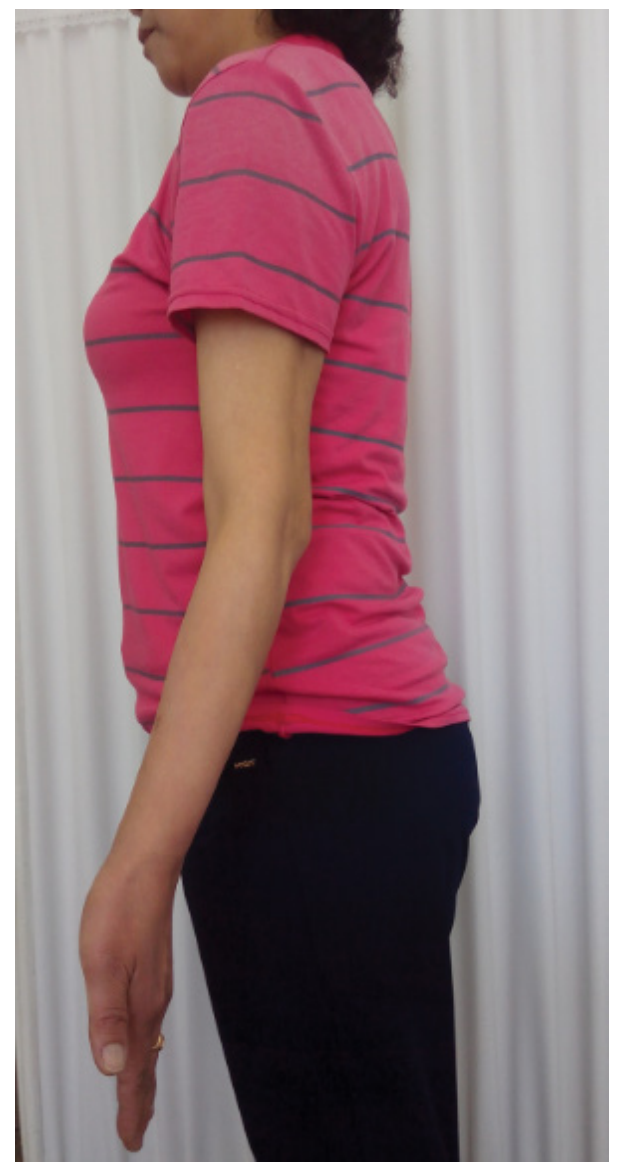

A

\section{Discussion}

The functional outcome following olecranon fracture fixation is generally good or excellent whatever method of fixation is used. The main complication following internal fixation of olecranon fractures is related to irritation caused by hardware.

Loss of motion is commonly encountered with patients typically losing $10^{\circ}-15^{\circ}$ of extension. The loss of elbow motion is worse in cases associated with fractures of the radial head, capitellum, coronoid or Monteggia fracture-dislocations [2,12].

The majority of patients recover a functional range of motion, frequently with small losses of extension, usually with no associated disability.

Previous studies of proximal ulna comminuted fracture, however, to our knowledge, have reported no cases of $\mathrm{HO}$ as a complication, despite the potential development of ectopic bone in the elbow.

Heterotopic ossification ( $\mathrm{HO}$ ), which is first described by Patin in 1962, is the formation of mature lamellar bone in nonosseous tissue. It is also termed heterotopic bone or ectopic osteogenesis (ossification and calcification).

The most common cause of $\mathrm{HO}$ is trauma such as

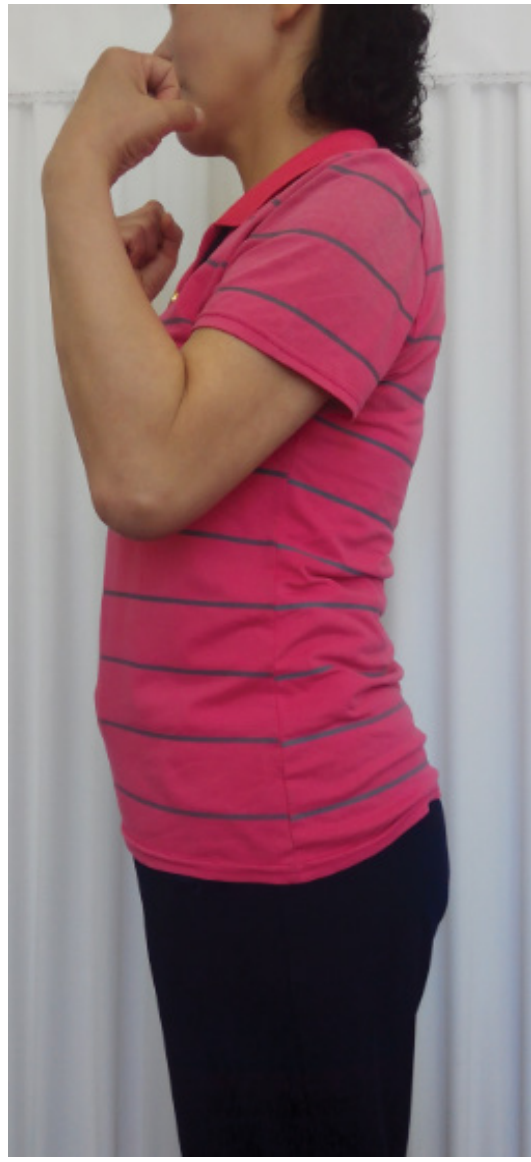

B

Figure 5: Recovered functional arc of the elbow (a) Extension loss is approximately 20 degree; (b) Flexion is approximately 130 degree. 
musculoskeletal injury, surgical trauma, or warfare injuries.

When it forms outside the joint capsule and periosteum. It causes pain, swelling and is usually associated with limited range of motion. That is why, this is an important problem throughout orthopaedic surgery [13-19].

HO may follow intracranial damage and is made more likely by delayed fixation and by passive stretching of the elbow [20].

It was reported that $\mathrm{HO}$ developed in approximately $3 \%$ of patients with a local injury of the elbow [21-24] and elbow $\mathrm{HO}$ occurs in $20 \%$ of patients with traumatic brain injury and forearm fractures $[22,25,26]$.

Otherwise, Robert W. Wysocki [27] reported a case of triceps muscle ectopic ossification and resultant elbow stiffness after application of recombinant human bone morphogenetic protein to a distal humerus nonunion site. This case was directly related to the use of OP-1. Most investigators agreed that the most frequent cause of heterotopic bone about the elbow is direct trauma, however, HO after ORIF of proximal ulna has not been reported yet, to our knowledge.

So now we are reporting a case of $\mathrm{HO}$ affecting the elbow motion after ORIF of proximal ulna comminuted fracture.

According to Hastings and Graham [22], this case seems class IIA.

In the present case we have experienced a complication of massive $\mathrm{HO}$ within the triceps directly over the olecranon where anatomical locking plate was lied, leading to marked loss of elbow motion.

We believe that anatomical locking plate fixation is much superior over other techniques, but this unpredicted complication which was directly related to the operation developed. The internal fixation in the present case has been rigid enough to ensure stability of fracture site, but we guess that the microtrauma caused by friction between the plate and triceps would be the main factor. After operation we allowed the patient to use her elbow as tolerated, and then formal physical therapy which was thought to aggravate the injury caused by incision and muscular dissection.

This is supported by the pattern and extent of the ectopic bone that formed in this case. Furthermore, we've not taken any measure to prevent the $\mathrm{HO}$, which could be also a cause of this unique case, to our knowledge.

Careful handling of tissue during any surgical procedure, especially around the hip and elbow, is also of importance to minimize any trauma and subsequent inflammation. But the role of proper surgical technique in the formation of heterotopic bone is difficult to quantitate, so various preventive modalities of $\mathrm{HO}$ have been discussed in the literature [28].

Different modalities used include diphosphonates, etidronate, and NSAIDs such as indomethacin and naproxen. Radiotherapy, Noggin, a BMP inhibitor, pulsed electromagnetic fields (PEMF), and free radical scavengers and $\mathrm{N}$-acetylcysteine [29-32].

But we ve not taken any the above mentioned measures because this complication has been very rarely reported.

We thought postoperative therapy was not proper in this case, either.

The principal of the HO treatment is appropriate immobilization for immature bone and physical therapy for a mature mass [30].

Just focusing on the early motion of the injured elbow in this case was more likely to promote the development of $\mathrm{HO}$.

In the present case, we wonder if immobilization for 3-4 weeks rather than early motion would be beneficial.

Although early motion and manipulation has been essential to prevent stiffness and has been reported to improve range of elbow motion, they may have predisposed to hematoma formation, scarring, and heterotopic ossification in this case.

From this experience, we do not recommend isolated physical therapy in patients with elbow injury, rather we recommend combined physical therapy with other preventive measures. Many authors agree that if ectopic bone around the elbow is causing or contributing to a loss of functional elbow motion, an operative procedure is warranted to remove the offending bone and release the joint capsule whether the motion limitation is partial or complete $[17,22]$.

Results of surgical excision of heterotopic ossification about the elbow have shown significant improvement in range of motion, independence, and quality of life in most cases [22,33-37].

They suggest that patients usually regain a full active range of motion within a few days of excision of the bony mass $[16,18]$.

In this case, the result of surgical excision was similar to the previous data $[17,22,33-37]$.

The patient was pain-free and obtained functional range of motion 3 weeks after the second procedure.

Although this is a very rare case, we recommend that postoperative therapy should be performed with caution in the elbow where formation of excess bone restricts motion. Unless the recovery of functional ROM is achieved as predicted, HO should be suspected, refraining from passively stretching the injured elbow.

In order to prevent postoperative HO, 
intraoperatively, surgical dissection should be performed as careful as possible, and postoperatively, management should involve all effective measures such as above mentioned ones.

\section{Compliance with Ethical Standards}

\section{Funding}

Thanks to the free medical care system in our country the state funds all the therapies, drugs, and so on.

\section{Conflict of interest}

This author, their immediate family, and any research foundation with which they are affiliated did not receive any financial payments or other benefits from any commercial entity related to the subject of this article.

\section{Ethical approval}

All procedures performed in this research were in accordance with the ethical standards of the institutional and national research committee and with the 1964 Helsinki declaration and its later amendments or comparable ethical standards.

\section{References}

1. Rommens PM, Kuchle R, Schneider RU, Reuter MM (2004) Olecranon fractures in adults: Factors influencing outcome. Injury 35: 1149-1157.

2. Lavigne G, Baratz M (2004) Fractures of the olecranon. J Am Soc Surg Hand 4: 94-102.

3. Ring D, Jupiter JB (1998) Fracture dislocation of the elbow. J Bone Joint Surg Am 80: 566-580.

4. Weber BG, Vasey H (1963) Osteosynthese bei Olecranonfraktur. Unfallmedizinische Berufskrankheiten 2: 90-96.

5. Anderson ML, Larson AL, Merton SM, Steinmann SP (2007) Congruent elbow plate fixation of olecranon fractures. $J$ Orthop Trauma 21: 386-393.

6. Joshi RP (1997) The hastings experience of the attenborough springs and rush nail for fixation of olecranon fractures. Injury 28: 455-458.

7. Hume MC, Wiss DA (1992) Olecranon fractures: A clinical and radiographic comparison of tension band wiring and plate fixation. Clin Orthop Relat Res, 229-235.

8. Wolfgang G, Burke F, Bush D, Parenti J, Perry J, et al. (1987) Surgical treatment of displaced olecranon fractures by tension band wiring technique. Clin Orthop Relat Res, 192-204.

9. Nowinski RJ, Nork SE, Segina DN, Benirschke SK (2000) Comminuted fracture-dislocations of the elbow treated with an AO wrist fusion plate. Clin Orthop Relat Res, 238-244.

10. Bailey CS, MacDermid J, Patterson SD, King GJ (2001) Outcome of plate fixation of olecranon fractures. J Orthop Trauma 15: 542-548.

11. Simpson NS, Goodman LA, Jupiter JB (1996) Contoured LC-DC plating of the proximal ulna. Injury 27: 411-417.

12. Hak DJ, Golladay GJ (2000) Olecranon fractures: Treatment options. J Am Acad Orthop Surg 8: 266-275.

13. Ahrengart L (1991) Periarticular heterotopic ossification after total hip arthroplasty. Risk factors and consequences. Clin Orthop Relat Res, 49-58.

14. Chouhan DK, Dhillon M, Bachhal V, Prabhakar S (2012) A traumatic heterotopic ossification of iliopsoas muscle: $A$ case report. Orthop Surg 4: 197-201.

15. Furukawa K-I (2008) Pharmacological aspect of ectopic ossification in spinal ligament tissues. Pharmacol Ther 118: 352-358.

16. Thorseth $\mathrm{K}$ (1968) A case of traumatic myositis ossificans in the iliopsoasmuscle. Acta Orthop Scand 39: 73-75.

17. Tonbul M, Ozen S, Tonbul AT (2014) Bilateral simultaneous heterotopic ossification of the reflected head of rectus femoris muscle: A case report and review of the literature. Case Rep Orthop 2014: 497075.

18. McCulloch PC, Bush-Joseph CA (2006) Massive heterotopic ossification complicating iliopsoas tendon lengthening: A case report. Am J Sports Med 34: 2022-2025.

19. Ritter MA, Vaughan RB (1977) Ectopic ossification after total hip arthroplasty. Predisposing factors, frequency, and effect on results. J Bone Joint Surg Am 59: 345-351.

20. Summerfield SL, DiGiovanni C, Weiss AP (1997) Heterotopic ossification of the elbow. J Should Elbow Surg 6: 321-332.

21. Garland DE, Blum CE, Waters RL (1980) Periarticular heterotopic ossification in head injured adults. Incidence and location. J Bone Joint Surg 62: 1143-1146.

22. Hastings H, Graham T (1994) The classification and treatment of heterotopic ossification about the elbow and forearm. Hand Clin 10: 417-437.

23. Peterson SL, Mani MM, Crawford CM, Neff JR, Hiebert JM (1989) Postburn heterotopic ossification: Insights for management decision making. J Trauma 29: 365-369.

24. Thompson HC, Garcia A (1967) Myositis ossificans: Aftermath of elbow injuries. Clin Orthop Relat Res 50: 129134.

25. Garland DE, O'Hollaren R (1982) Fractures and dislocations about the elbow in the head-injured adult. Clin Orthop Relat Res, 38-41.

26. Garland DE, Dowling V (1983) Forearm fractures in the head-injured adult. Clin Orthop Relat Res, 190-196.

27. Wysocki RW, Cohen MS (2007) Ectopic ossification of the triceps muscle after application of bone morphogenetic protein-7 to the distal humerus for recalcitrant nonunion: $A$ case report. J Hand Surg 32: 647-650.

28. Baird EO, Kang QK (2009) Prophylaxis of heterotopic ossification-an updated review. J Orthop Surg Res 4: 12.

29. Bek D, Beksac B, Della Valle AG, Sculco TP, Salvati EA (2009) Aspirin decreases the prevalence and severity of heterotopic ossification after 1-stage bilateral total hip arthroplasty for osteoarthrosis. J Arthroplasty 24: 226-232.

30. Banovac K (2000) The effect of etidronate on late development of heterotopic ossification after spinal cord injury. J Spinal Cord Med 23: 40-44.

31. McAuliffe J (1997) Early excision of heterotopic ossification about the elbow followed by radiation therapy. J Bone Joint Surg Am 79: 749-755.

32. Vavken P, Castellani L, Sculco TP (2009) Prophylaxis of heterotopic ossification of the hip: Systematic review and metaanalysis. Clin Orthop Relat Res 467: 3283-3289. 
33. Djurickovic S, Meek RN, Snelling CF, Broekhuyse HM, Blachut PA, et al. (1996) Range of motion and complications after postburn heterotopic bone excision about the elbow. $J$ Trauma 41: 825-830.

34. Garland DE (1991) A clinical perspective on common forms of acquired heterotopic ossification. Clin Orthop Relat Res, 13-29.

35. Garland DE (1991) Surgical approaches for resection of heterotopic ossification in traumatic brain-injured adults. Clin Orthop Relat Res, 59-70.
36. Garland DE, Hanscom DA, Keenan MA, Smith C, Moore T (1985) Resection of heterotopic ossification in the adult with head trauma. J Bone Joint Surg Am 67: 1261-1269.

37. Kolessar DJ, Katz SD, Keenan ME (1996) Functional outcome following surgical resection of heterotopic ossification in patients with brain injury. J Head Trauma Rehabil 44: 4. 